\title{
Low temperature in situ formation of cobalt in silicon nitride toward functional nitride nanocomposites ${ }^{\dagger}$
}

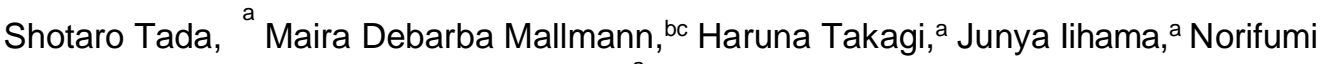 \\ Asakuma, ${ }^{\text {a }}$ Toru Asaka, ${ }^{\text {a }}$ Yusuke Daiko, ${ }^{a}$ Sawao Honda, ${ }^{a}$ \\ Rafael Kenji Nishihora, ${ }^{\text {bc Ricardo Antonio Francisco Machado, }{ }^{c} \text { Samuel Bernard }}{ }^{\mathrm{b}}$ \\ and Yuji Iwamoto *a
}

This work highlights the first demonstration of a low-temperature in situ formation of Co nanocrystallites embedded within an amorphous silicon nitride matrix through careful control of the chemistry behind material design using perhydropolysilazane (PHPS) as a $\mathrm{Si}_{3} \mathrm{~N}_{4}$ precursor further coordinated with $\mathrm{CoCl}_{2}$ and ammonia as a pyrolysis atmosphere. The Co nucleation was allowed to proceed at temperatures as low as $4008 \mathrm{C}$ via thermal decomposition of $\mathrm{Co}_{2} \mathrm{~N}$ pre-formed in situ by the reaction of $\mathrm{CoCl}_{2}$ with the Si centers of PHPS at the early stage of pyrolysis (220-350 8C).

Material discovery is a key element in the innovation cycle of energy conversion, transmission and storage technologies. ${ }^{1}$ In this category of energy-focused materials, advanced ceramics appear to be high value-added products with performances that are tailored via their rational and elaborate designs. ${ }^{2-6}$ Ceramic processing methods based on molecular engineering and precursor chemistry are well appropriate approaches to design such materials that can reach performances far beyond those developed by more conventional synthesis routes. ${ }^{7-10}$ A very convenient precursor route is the polymer derived ceramics

(PDCs) route which allows fine control over the chemical composition of the final ceramic materials as well as their phase distribution and nanostructure. ${ }^{11,12}$ This offers enhanced or novel functional properties which have been recently highlighted in metal/Si-based (oxy-)carbide and carbonitride matrix composites such as $\mathrm{Ni} / \mathrm{SiC},{ }^{13} \mathrm{Ni} / \mathrm{SiOC},{ }^{14} \mathrm{Ni} / \mathrm{SiCN}(\mathrm{O}){ }^{15}$ and $\mathrm{M} / \mathrm{SiCN}$ $\left(\mathrm{M}=\mathrm{Pd},{ }^{16} \mathrm{Ru},{ }^{16} \mathrm{Pd}_{2} \mathrm{Ru},{ }^{17} \mathrm{Cu},{ }^{18,19} \mathrm{Ir},{ }^{16,20} \mathrm{Ni},{ }^{21} \mathrm{Pt},{ }^{22,23} \mathrm{Co},{ }^{24} \mathrm{Fe}^{25}\right)$ derived from metal-modified polycarbosilanes, polysiloxanes and polysilazanes, respectively. In particular, as reported by Kempe et al.,

\footnotetext{
${ }^{a}$ Department of Life Science and Applied Chemistry, Graduate School of Engineering, Nagoya Institute of Technology, Gokiso-cho, Showa-ku, Nagoya 466-8555, Japan

${ }^{b}$ University of Limoges, CNRS, IRCER, UMR 7315, Limoges, F-87000, France

${ }^{c}$ Chemical Engineering, Federal University of Santa Catarina,

Florianópolis, 88010-970, Brazil
}

the polymer-derived $\mathrm{M} / \mathrm{SiCN}$ nanocomposites are attractive as robust and reusable catalysts which can be applied to various catalytic reactions by changing the metal nanoparticle component: dehydrogenation by $\mathrm{Pd} ;{ }^{16}$ hydrogenation and dehydrogenation of $\mathrm{N}$-heterocycles by $\mathrm{Pd}_{2} \mathrm{Ru} ;{ }^{17}$ selective hydrocarbon oxidation by $\mathrm{Cu} ;{ }^{18,19}$ dehydrogenative condensation of secondary alcohols and 1,2-amino alcohols by $\mathrm{Ir} ;{ }^{20}$ chemoselective hydrogenation of nitroarenes by $\mathrm{Ni},{ }^{21} \mathrm{Co}^{24}$ and $\mathrm{Fe},{ }^{25}$ and hydrolysis of sodium borohydride by $\mathrm{Pt}^{23}$

In contrast, the design of metal/Si-based composites in nitride matrix systems (i.e., $\mathrm{M} / \mathrm{Si}_{3} \mathrm{~N}_{4}$ ) has never been demonstrated and it remains highly challenging while nitrides can be particularly interesting for catalysis as a support and/or as a catalyst itself. ${ }^{26-31}$ This is mainly caused by the reactivity of the central metal cations distributed in the polysilazane network with ammonia (used as atmosphere to form $\mathrm{Si}_{3} \mathrm{~N}_{4}$ from polysilazanes) forming a metal nitride nanophase distributed in the $\mathrm{Si}_{3} \mathrm{~N}_{4}$ matrix. This observation is well illustrated in the recent reports on $\mathrm{Si}_{3} \mathrm{~N}_{4}$-based nanocomposites including $\mathrm{TiN} / \mathrm{Si}_{3} \mathrm{~N}$ 32,33 and $\mathrm{VN} / \mathrm{Si} \mathrm{N}_{3}$ compounds. Among them, the TiN/Si $\mathrm{N}_{4}$ nanocomposites exhibited strong synergy with Pt nanoparticles, which were homogeneously deposited in a second synthesis step onto the nanocomposite support. This resulted in excellent catalytic performance for dehydrogenation of sodium borohydride in water. ${ }^{33}$ Thus, this report confirmed the attractivity of nitrides for catalysis. To simplify this two-step process, and avoid the use of precious metals such as $\mathrm{Pt}$ while forming $\mathrm{Si}_{3} \mathrm{~N}_{4}$ supporting the catalytically active phase (i.e., $\mathrm{M} / \mathrm{Si}_{3} \mathrm{~N}_{4}$ ) in a one-step process, we describe the coordination of a polysilazane (PHPS) with cobalt chloride $\left(\mathrm{CoCl}_{2}\right)$ allowing the in situ formation of Co during the further thermo-chemical conversion of the PHPS into $\mathrm{Si}_{3} \mathrm{~N}_{4}$ in flowing ammonia. The unique low-temperature in situ formation of Co within the $\mathrm{Si}_{3} \mathrm{~N}_{4}$ matrix is discussed based on a complete set of characterization techniques including elemental analyses, Xray diffraction (XRD), thermogravimetric - mass spectrometric (TG-MS) analyses, infrared spectroscopy, ultraviolet-visible (UV-Vis) spectroscopy and transmission electron microscopy 
(TEM) observations. The basis of our approach comes first from the design of a suitable highly pure synthetic precursor in which uniform chemical composition is established at a molecular scale. Thus, we mixed $\mathrm{CoCl}_{2}$ with PHPS which only contains $\mathrm{Si}, \mathrm{N}$ and $\mathrm{H}$ elements in a controlled $\mathrm{Co} / \mathrm{Si}$ molar ratio of 0.2 to form a compound labeled Co-PHPS. The synthesis is performed in toluene and directed to keep a homogeneous distribution of $\mathrm{CoCl}_{2}$ throughout the PHPS network (without direct reaction). Then, the precursor is heat-treated under ammonia to form an unstable (thermally) metal nitride phase at low temperatures, while avoiding the formation of free $\mathrm{Si}$ at higher temperatures as known using PHPS, ${ }^{35,36}$ thus leading to $\mathrm{Co} / \mathrm{Si}_{3} \mathrm{~N}_{4}$ compounds at low and intermediate temperatures as discussed below.

Pyrolysis leads to samples labeled as Co/SiNX ( $X$ being the temperature at which the material has been heat-treated) with tuned phase composition and nano-/microstructure organiza-

tion according to the pyrolysis temperature. The chemical compositions of the Co/SiNX samples are listed in Table 1. All

the procedures for Co-PHPS synthesis, subsequent heat treatment and characterization of Co/SiNX are reported in the ESI. $\dagger$

Chemical compositions of the Co/SiNX samples are discussed in relation to their XRD patterns (Fig. 1), TG-MS experiments (Fig. 2) and FTIR spectroscopy (Fig. 3). The Co/SiN400 sample exhibits three characteristic diffraction peaks assigned to a-Co (JCPDS No. 00-015-0806 at 2y = 48.6, 52.0, and 55.61) along with a residual component of $\mathrm{CoCl}_{2}$ (JCPDS No. 01-085-0446) and $\mathrm{NH}_{4} \mathrm{Cl}$ (JCPDS No. 01-073-0365).

Additionally, two small diffraction peaks appear at $2 \mathrm{y}$ angles of 46.5 and 50.41, indicating the formation of cobalt nitride $\left(\mathrm{Co}_{2} \mathrm{~N}\right.$, JCPDS No. 04-004-4638). Then, at $5001 \mathrm{C}$ (Co/SiN500

sample), the $\mathrm{Co}_{2} \mathrm{~N}$ disappears while the metallic a-Co forms. At $8001 \mathrm{C}$ (Co/SiN800 sample), two distinct diffraction peaks appear at 51.8 and 60.71 , which are assigned to b-Co (JCPDS

No. 01-089-4308) along with a-Co, and several minor peaks related to both a- and $\mathrm{b}-\mathrm{Si}_{3} \mathrm{~N}_{4}$ were also identified. The $\mathrm{NH}_{4} \mathrm{Cl}$ XRD peaks disappeared because of its vaporization when heated above $5001 \mathrm{C}$; this was confirmed by its condensation in the cool parts (extremities) of the furnace tube. Finally, the Co/SiN1000 sample exhibits the formation of thermodynamically favorable cobalt silicide ( $\mathrm{Co}_{2} \mathrm{Si}$, JCPDS No. 01-089-4181) in addition to the a- and $\mathrm{b}-\mathrm{Si}_{3} \mathrm{~N}_{4}$ phases. Thus, $\mathrm{Co} / \mathrm{Si}_{3} \mathrm{~N}_{4}$ (amorphous and crystalline) composites are generated at temperatures below $8001 \mathrm{C}$. In order to investigate this lowtemperature in situ formation of a/b-Co, TG-MS analyses have been performed. The TG-curve (Fig. 2a) exhibits two main

Table 1 Chemical composition of the Co/SiNX samples

\begin{tabular}{|c|c|c|c|c|c|c|}
\hline \multirow[b]{3}{*}{ Name } & \multicolumn{5}{|c|}{ Composition/wt\% } & \multirow{3}{*}{$\begin{array}{l}\text { Composition/at\% } \\
\text { Atomic ratio to } \mathrm{Si}\end{array}$} \\
\hline & \multicolumn{2}{|c|}{$\begin{array}{l}\mathrm{EDS}(\mathrm{Co} / \mathrm{Si} \\
\text { ratio) }\end{array}$} & \multicolumn{3}{|c|}{$\begin{array}{l}\text { Elemental analy- } \\
\text { sis/wt\% }\end{array}$} & \\
\hline & $\overline{\mathrm{Si}}$ & $\mathrm{Co}$ & $\overline{\mathrm{C}}$ & $\mathrm{O}$ & & \\
\hline$\overline{\mathrm{CO} / \mathrm{SiN} 400}$ & 44.83 & 35.23 & 0.80 & 16.84 & 2.30 & $\mathrm{Si}_{1} \mathrm{C}$ \\
\hline Co/SiN500 & 57.40 & 22.32 & 0.93 & 16.36 & 2.99 & $\mathrm{Si}_{1} \mathrm{Cc}$ \\
\hline Co/SiN800 & 52.89 & 16.70 & 0.50 & 23.73 & 6.18 & $\mathrm{Si}_{1} \mathrm{Co}_{0.15} \mathrm{Co}_{0.02} \mathrm{~N}_{0.90} \mathrm{O}_{0.21}$ \\
\hline Co/SiN1000 & 53.84 & 16.08 & 0.01 & 26.09 & 3.98 & $8 \mathrm{Si}_{1} \mathrm{Co}_{0.14} \mathrm{Co}_{0.00} \mathrm{~N}_{0.97} \mathrm{O}_{0.13}$ \\
\hline
\end{tabular}

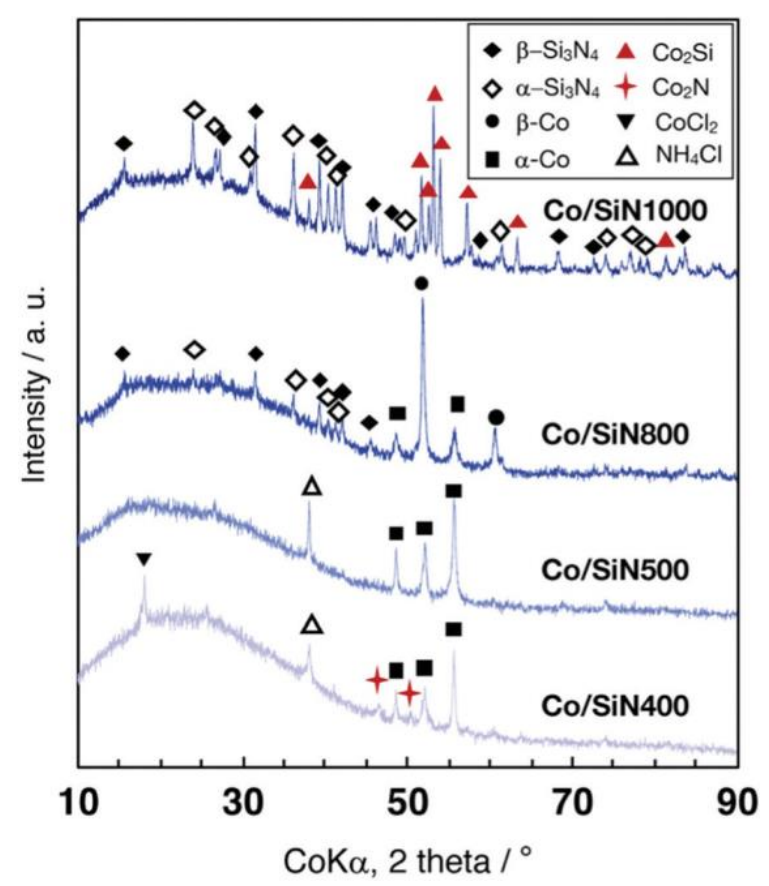

Fig. 1 XRD patterns of Co/SiNX samples.

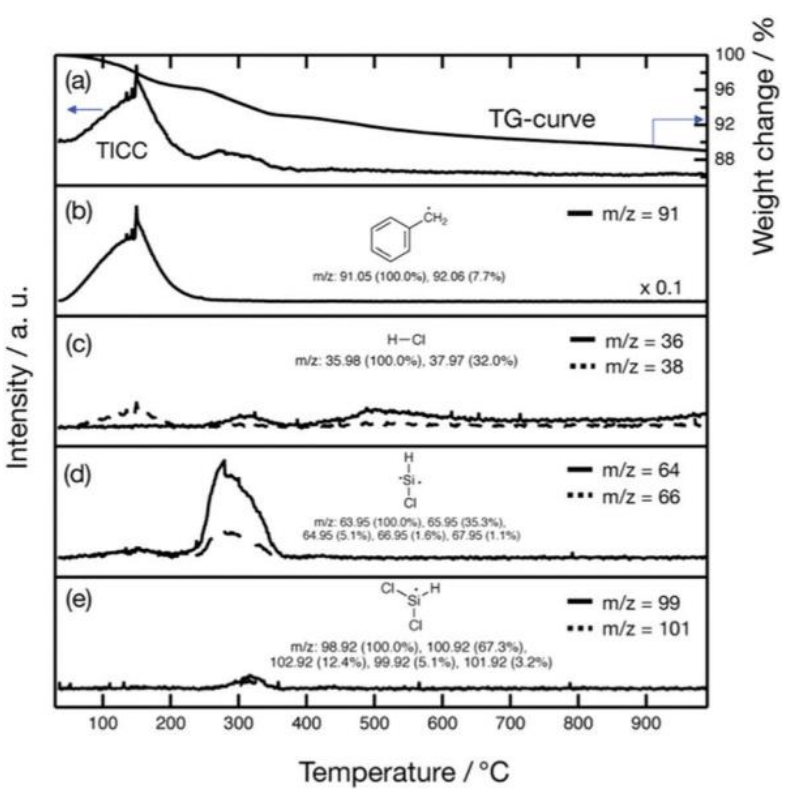

Fig. 2 TG-MS analyses under flowing He of the Co-PHPS sample:

(a) a TG-curve and a total ion current chromatogram, (b-e) the simultaneous monitoring of gaseous products formed in situ.

weight loss regions at 50-220 1C and 220-350 1C. The coupled MS analysis reveals that the main evolved component at 50$2201 \mathrm{C}$ is toluene $\left(\mathrm{C}_{6} \mathrm{H}_{5} \mathrm{CH}_{3}, \mathrm{~m} / z=91\right.$, Fig. $\left.2 \mathrm{~b}\right)$ as the reaction

solvent medium, while at 220-350 1C, the dominant gaseous species are chloride fragments, such as hydrochloric acid $(\mathrm{HCl}$, $m / z=36$ and 38, Fig. 2c), monochlorosilane $(\mathrm{m} / z=64$ and 66, Fig. 2d) and dichlorosilane $(m / z=99$ and 101, Fig. 2e) species. 


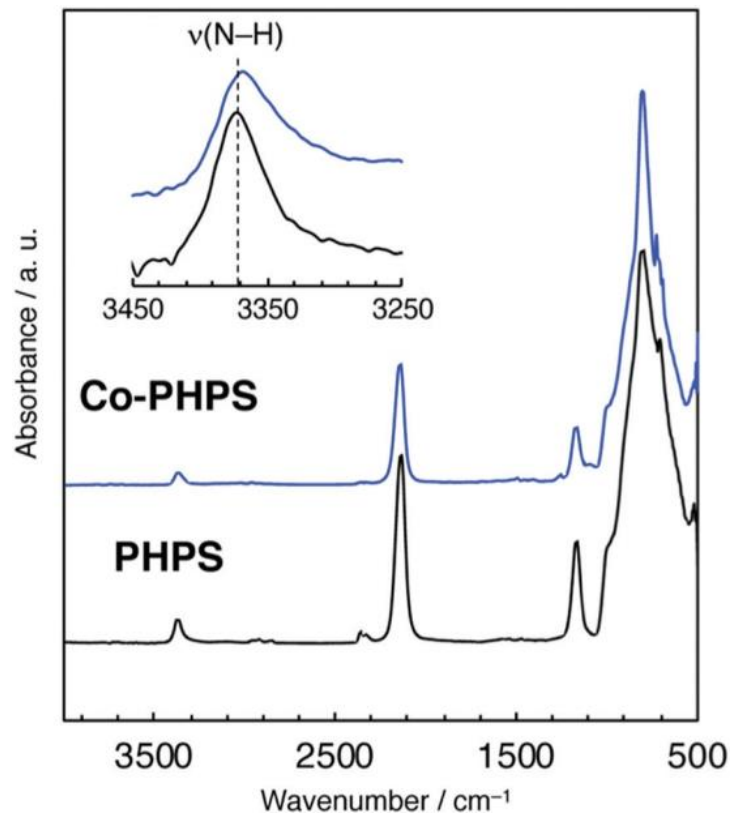

Fig. 3 ATR-IR spectra for the as-received PHPS and Co-modified PHPS.

As shown in Fig. S1 (ESI $\uparrow$ ), a color change from blue to gray was observed for the $\mathrm{CoCl}_{2}$-dispersed PHPS solution after reflux at $110 \mathrm{1C}$ for $12 \mathrm{~h}$. The visible color change was also monitored by UV-Vis absorption spectroscopy (Fig. S2, ESI $\dagger$ ): as-received $\mathrm{CoCl}_{2}$ exhibits a broad peak around $600 \mathrm{~nm}$ attributed to octahedral coordination of $\mathrm{CoCl}_{2},{ }^{37,38}$ while the Co-PHPS sample recovered after the 110 1C-refluxing in toluene presents

additional absorption bands at 670 and $700 \mathrm{~nm}$ assigned to typical bands of tetrahedral coordination which were attributed to the formation of $\mathrm{CoCl}_{2} \mathrm{~L}_{2}\left(\mathrm{~L}=\right.$ ligands). ${ }^{37,38}$ In addition, according to the FTIR spectrum of the Co-PHPS shown in Fig. 3, the characteristic bands at $3370 \mathrm{~cm}^{-1}(\mathrm{nN}-\mathrm{H})^{36}$ of PHPS slightly shift towardlower wavenumber of $3365 \mathrm{~cm}^{-1}$, suggesting the $\mathrm{CoCl}_{2}$ coordination to the $\mathrm{NH}$ group of PHPS during the precursor synthesis. We therefore suggest that the reaction between PHPS and $\mathrm{CoCl}_{2}$ better proceeded during the pyrolysis, and the $\mathrm{NH}_{4} \mathrm{Cl}$ species detected in the XRD patterns of the Co/SiN400 and Co/SiN500 samples (Fig. 1) are by-products resulting from the nucleation reaction between $\mathrm{HCl}$ formed in situ and the gaseous $\mathrm{NH}_{3} \cdot{ }^{39}$ As shown in Table 1 , the $\mathrm{Co} / \mathrm{Si}$ ratio of the $\mathrm{Co} / \mathrm{SiN} 400$ sample (0.37) was apparently higher than the nominal Co/Si ratio of Co-PHPS (0.2), which can be explained by the elimination of chlorosilanes at 220-350 1C (Fig. 2(d) and

(e)), i.e., the number of $\mathrm{SiH}$ groups decreases. Furthermore, from 400 to $5001 \mathrm{C}$, the $\mathrm{N} / \mathrm{Si}$ atomic ratio decreased from 0.75 to 0.57 (Co/SiN500). This corresponds to the reported thermal decom- position of $\mathrm{Co}_{2} \mathrm{~N}$ at $350-450$ 1C. ${ }^{40}$ Consequently, these results indicate that the following reactions proceed stepwise:

(i) At 220-350 1C, Si-N cleavages in the Co-PHPS sample proceed via reaction of the Si center and NH group of PHPS with $\mathrm{CoCl}_{2}$ associated with the elimination of chlorosilanes and $\mathrm{HCl}$ to afford $\mathrm{Co}_{2} \mathrm{~N}$, respectively.

(ii) At $350-4501 \mathrm{C}, \mathrm{Co}_{2} \mathrm{~N}$ thermally decomposes to yield metallic-Co.
The N/Si ratio of the Co/SiNX samples in Table 1 increased during pyrolysis from 500 to $10001 \mathrm{C}$, indicating the occurrence of nitridation of the evolutive polymer under ammonia above $5001 \mathrm{C} .{ }^{41}$ Moreover, the crystallization of $\mathrm{Si}_{3} \mathrm{~N}_{4}$ started at $8001 \mathrm{C}$, which was approximately $4001 \mathrm{C}$ lower than that of Co-free PHPS-derived amorphous silicon nitride. ${ }^{36}$ Table 2 presents the

relationship between the pyrolysis temperature and the average crystallite sizes evaluated for a-Co(101) and b-Co(111). The initial low-temperature crystallization (400 1C) of a-Co yields crystallites of approximately $106 \mathrm{~nm}$. Then, consistent with the pyrolysis temperature, the a-Co nanocrystallites decrease their size via phase transformation to thermally favorable b-Co, and the Scherrer analysis indicated an average b-Co nanocrystallite size of $74.4 \mathrm{~nm}$ for the Co/SiN800 sample.

To gather micro- and nanostructural information, TEM investigations were performed on the Co/SiN800 sample (Fig. 4). The TEM image of the Co/SiN800 sample (Fig. 4) shows aggregated nanocrystallites with dark contrast and diameter of about $40-80 \mathrm{~nm}$ which are embedded in a network with the typical phase contrast of amorphous (or poorly crystallized) materials. The corresponding selected area electron diffraction (SAED) patterns confirm the indexation of both a- and b-Co (inset in Fig. 4). Neither silicon segregations nor inclusions along grain boundaries are observed, while dark spots with several nanometers in size (typical ones are indicated by arrows) are observed which suggested that the crystallite size distribution of Co embedded within the silicon nitride matrix is bimodal: several nanometers and 40 to $80 \mathrm{~nm}$.

In conclusion, the addition of cobalt chloride $\left(\mathrm{CoCl}_{2}\right)$ on perhydropolysilazane (PHPS) in toluene in a $1 / 5$ molar ratio generated a cobalt-coordinated PHPS that was heat-treated in flowing ammonia in the temperature range of 400 to $8001 \mathrm{C}$ to favor the in situ growth of Co nanoparticles in an amorphous silicon nitride matrix. The highlights can be summarized as follows:

(1) Formation of $\mathrm{Co}_{2} \mathrm{~N}$ formed in situ by the reaction of $\mathrm{CoCl}_{2}$ with the Si center and NH group of PHPS at 220-350 1C.

(2) Co started growing at temperature as low as $4001 \mathrm{C}$ via the thermal decomposition of $\mathrm{Co}_{2} \mathrm{~N}$.

(3) Crystallization of the amorphous silicon nitride matrix proceeded at $8001 \mathrm{C}$.

Further investigations on the molecular structure of the single-source precursors and subsequent pyrolysis conditions at the low temperatures are still in progress. Therefore, this study paves the way for the rational one-step synthesis of metal/ nitride nanocomposites that may be applied in a wide range of catalysis-assisted reactions for energy-related fields. These opportunities are now being addressed. It is anticipated that

Table 2 Relationship between the pyrolysis temperature and the average crystallite sizes evaluated for a-Co(101) and b-Co(111)

\begin{tabular}{llll}
\hline & Co/SiN400 & Co/SiN500 & CoSiN800 \\
\hline a-Co(101) & 106 & 76 & 29 \\
b-Co(111) & - & - & 74
\end{tabular}




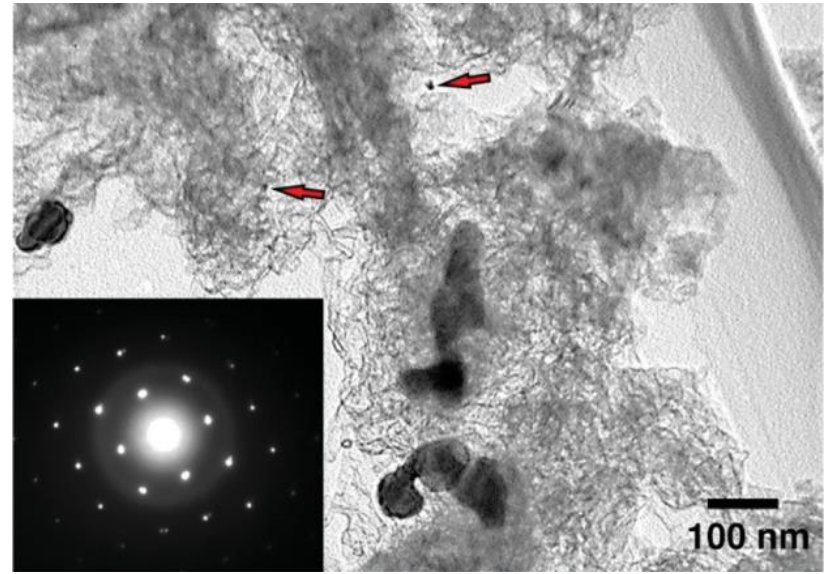

Fig. 4 TEM image of the Co/SiN800 sample, and the corresponding SAED patterns obtained from the aggregated nanocrystallites with dark contrast, and the arrows pointing to several nanometer sized Co crystallites.

this will lead to a host of structural and functional applications for a new generation of advanced ceramics.

This work was partially supported by JSPS KAKENHI Grant Number JP20K05076. Dr Samuel Bernard and Prof. Yuji Iwamoto would like to thank CNRS who financially supported the present work via the International Research Project (IRP) 'Ceramics materials for societal challenges'.

\section{Notes and references}

1 D. Gielen, F. Boshell and D. Saygin, Nat. Mater., 2016, 15, 117-120. 2 Y. Zhong, X. Xia, F. Shi, J. Zhan, J. Tu and H. J. Fan, Adv. Sci., 2016, 3, 1500286.

3 S. Klemenz, J. Schuch, S. Hawel, A.-M. Zieschang, B. Kaiser, W. Jaegermann and B. Albert, ChemSusChem, 2018, 11, 3150-3156.

4 M.-S. Balogun, Y. Huang, W. Qiu, H. Yang, H. Ji and Y. Tong, Mater. Today, 2017, 20, 425-451.

5 E. W. Awin, A. Lale, K. C. H. Kumar, S. Bernard and R. Kumar, Appl. Surf. Sci., 2020, 508, 144953-144961.

6 M. Eckardt, M. Zaheer and R. Kempe, Sci. Rep., 2018, 8, 2567.

7 C. Sanchez, C. Boissiere, S. Cassaignon, C. Chaneac, O. Durupthy, M. Faustini, D. Grosso, C. Laberty-Robert, L. Nicole, D. Portehault, F. Ribot, L. Rozes and C. Sassoye, Chem. Mater., 2014, 26, 221-238. 8 S. Clément and A. Mehdi, Molecules, 2020, 25, 2538-2544.

9 C. Sanchez, L. Rozes, F. Ribot, C. Laberty-Robert, D. Grosso, C. Sassoye, C. Boissiere and L. Nicole, C. R. Chim., 2010, 13, 3-39.

10 A. Lale, M. Schmidt, M. D. Mallmann, A. V. A. Bezerra, E. D. Acosta, R. A. F. Machado, U. B. Demirci and S. Bernard, Surf. Coat. Technol., 2018, 350, 569-586.
11 P. Colombo, G. Mera, R. Riedel and G. D. Sorarù, J. Am. Ceram. Soc., 2010, 93, 1805-1837.

12 E. Ionescu, H. J. Kleebe and R. Riedel, Chem. Soc. Rev., 2012, 41, 5032-5052.

13 M. Zaheer, J. Hermannsdörfer, W. P. Kretschmer, G. Motz and R. Kempe, ChemCatChem, 2014, 6, 91-95.

14 D. Schumacher, M. Wilhelm and K. Rezwan, J. Am. Ceram. Soc., 2020, 103, 2991-3001.

15 M. Seifollahi Bazarjani, H. J. Kleebe, M. M. Müiller, C. Fasel, M. Baghaie Yazdi, A. Gurlo and R. Riedel, Chem. Mater., 2011, 23, 4112-4123.

16 D. Forberg, T. Schwob and R. Kempe, Nat. Commun., 2018, 9, 1751.

17 D. Forberg, T. Schwob, M. Zaheer, M. Friedrich, N. Miyajima and R. Kempe, Nat. Commun., 2016, 7, 13201.

18 G. Glatz, T. Schmalz, T. Kraus, F. Haarmann, G. Motz and R. Kempe, Chem. - Eur. J., 2010, 16, 4231-4238.

19 M. Zaheer, T. Schmalz, G. Motz and R. Kempe, Chem. Soc. Rev., 2012, 41, 5102-5116.

20 D. Forberg, J. Obenauf, M. Friedrich, S.-M. Hühne, W. Mader, G. Motz and R. Kempe, Catal. Sci. Technol., 2014, 4, 4188-4192.

21 G. Hahn, J.-K. Ewert, C. Denner, D. Tilgner and R. Kempe, ChemCatChem, 2016, 8, 2461-2465.

22 M. Kamperman, A. Burns, R. Weissgraeber, N. van Vegten, S. C. Warren, S. M. Gruner, A. Baiker and U. Wiesner, Nano Lett., 2009, 9, 2756-2762.

23 S. M. Sachau, M. Zaheer, A. Lale, M. Friedrich, C. E. Denner, U. B. Demirci, S. Bernard, G. Motz and R. Kempe, Chem. - Eur. J., 2016, 22, 15508-15512.

24 T. Schwob and R. Kempe, Angew. Chem., Int. Ed., 2016, 55, 1517515179.

25 C. Bäumler and R. Kempe, Chem. - Eur. J., 2018, 24, 8989-8993.

26 Y. Han, X. Yue, Y. Jin, X. Huang and P. K. Shen, J. Mater. Chem. A, 2016, 4, 3673-3677.

27 M.-S. Balogun, W. Qiu, W. Wang, P. Fang, X. Lu and Y. Tong, J. Mater. Chem. A, 2015, 3, 1364-1387.

28 W. Yang, S. Rehman, X. Chu, Y. Hou and S. Gao, ChemNanoMat, 2015, 1, 376-398.

29 M.-S. Balogun, Y. Huang, W. Qiu, H. Yang, H. Ji and Y. Tong, Mater. Today, 2017, 20, 425-451.

30 J. S. J. Hargreaves, Coord. Chem. Rev., 2013, 257, 2015-2031.

31 S. Dong, X. Chen, X. Zhang and G. Cui, Coord. Chem. Rev., 2013, 257, 1946-1956.

32 M. C. Bechelany, V. Proust, A. Lale, P. Miele, S. Malo, C. Gervais and S. Bernard, Chem. - Eur. J., 2017, 23, 832-845.

33 A. Lale, M. D. Mallmann, S. Tada, A. Bruma, S. Özkar, R. Kumar, M. Haneda, R. A. Francisco Machado, Y. Iwamoto, U. B. Demirci and S. Bernard, Appl. Catal., B, 2020, 272, 118975.

34 C. Zhou, A. Ott, R. Ishikawa, Y. Ikuhara, R. Riedel and E. Ionescu, J. Eur. Ceram. Soc., 2020, 40, 6280-6287.

35 M. Biesuz, P. Bettotti, S. Signorini, M. Bortolotti, R. Campostrini, M. Bahri, O. Ersen, G. Speranza, A. Lale, S. Bernard and G. D. Sorarù, Nanotechnology, 2019, 30, 255601.

36 Y. Iwamoto, K. I. Kikuta and S. I. Hirano, J. Ceram. Soc. Jpn., 2000, 108, 350-356.

37 C. L. Hussey and T. M. Laher, Inorg. Chem., 1981, 20, 4201-4206.

38 I. Sava, M.-D. Damaceanu and G. Lisa, J. Polym. Res., 2016, 23, 130

39 S. Thompson, P. D. Shipman, S. P. Shipman and T. J. Zurlinden, J. Chem. Phys., 2019, 150, 154306.

40 L. Maya, M. Paranthaman, J. R. Thompson, T. Thundat and R. J. Stevenson, J. Appl. Phys., 1996, 79, 7905-7910.

41 G. T. Burns and G. Chandra, J. Am. Ceram. Soc., 1989, 72, 333-337. 